\title{
Identidades colectivas y mecanismos de participación social en la población La Victoria, 1983-1987
}

\author{
Eduardo Garín Abarzúa' \\ Recibido: 18 de julio de 2017 - Aprobado: 15 de septiembre de 2017
}

\begin{abstract}
Resumen
El presente artículo relaciona las identidades colectivas de los pobladores de La Victoria con los mecanismos de participación social entre 1983 y 1987. A partir de su estudio es posible observar la reafirmación de sus identidades, asociadas a la organización permanente de los pobladores. Como hipótesis proponemos que es posible señalar que los mecanismos de participación no solo fueron elementos tendientes a reivindicar posiciones políticas 0 programáticas, sino que también tuvieron un efecto en la reafirmación de sus identidades colectivas en términos culturales asociados a las formas de concebir la realidad en esta zona urbana popular.
\end{abstract}

Palabras clave: Identidad colectiva, Movimiento de pobladores, población La Victoria, participación social.

\section{Collective identities and mechanisms of social participation in} La Victoria settlement, 1983-1987

\begin{abstract}
This article relates the collective identities of La Victoria's inhabitants to mechanisms of social involvement between 1983 and 1987. From this study, it is possible to observe the reaffirmation of their identities, associated with dwellers permanently organized. We propose as a hypothesis that it is possible to point out that the mechanisms of involvement were not only elements tending to claim political or programmatic positions, but also had an effect reaffirming their collective identities in cultural terms in relation to the way of conceiving reality in this popular urban area.
\end{abstract}

Keywords: Collective identity, slum dwellers movement, La Victoria settlement, social involvement.

1 Chileno. Profesor de Historia, Estudiante del Programa de Magíster en Historia, Universidad de Santiago de Chile. El presente artículo es parte del proyecto de tesis de Magister en Historia centrada en el estudio de las "identidades espejo" en La Victoria, en tanto considera las identidades "propias" y cómo "otros" observan a la población, entre los años 1983 y 1999. E-mail: eduardo.garin.a@usach.cl 


\title{
Identidades coletivas e mecanismos de participação social na população A Victoria, 1983-1987
}

\begin{abstract}
Resumo
0 presente artigo relaciona as identidades coletivas dos habitantes da Victoria com os mecanismos de participação social entre 1983 e 1987. A partir do seu estudo é possível observar a reafirmação de suas identidades, associada à organização permanente dos povoadores. Como hipótese, propomos que seja possível apontar que os mecanismos de participação não foram somente elementos que tendem a reivindicar posições políticas ou programáticas, mas também que tiveram um efeito na reafirmação de suas identidades coletivas em termos culturais associados aos modos de conceber a realidade nessa área urbana popular.
\end{abstract}

Palavras-chave: Identidade coletiva, Movimento de povoadores, população a Victoria, participação social.

Una de las dimensiones, acaso la más llamativa del mundo poblacional, es aquella de orden cultural, estrechamente vinculada con el planteamiento del historiador Mario Góngora, quien señaló que "la cultura popular sigue entretanto su curso intemporal, sujeto a sus propias leyes" (Salinas, 1992). Esta valoración, en apariencia esencialista y folklorista, permite dar cuenta de un itinerario histórico y temporal de los pobladores urbanos durante la segunda mitad del siglo XX, quienes otorgan prioridad a la construcción de sentidos identitarios inherentes a su condición de clase popular y que son subvalorados por la lógica dominante. ${ }^{2}$ Claro está que estas mismas identidades colectivas se han desarrollado bajo distintas etapas desde el establecimiento de la población La Victoria en 1957, hasta hoy, con distintos cambios y continuidades a su haber, y no sólo eso, han sabido configurar distintos grados de "experiencia" de clase asociados al "pertenecer" y "resistir" en medio del mundo de los pobladores (Thompson, 1989). En esta línea, el presente artículo tiene como objetivo relacionar la categoría de identidades colectivas con los mecanismos de participación social desarrollados en esta población urbana durante las "jornadas de protesta nacional" 3 contra la dictadura de Pinochet entre los años 1983 a 1987 en tanto es el medio o canal para reafirmar estas construcciones identitarias. La periodización temporal escogida considera desde 1983 -correspondiente a la reactivación de un movimiento social de oposición visible contra la dictadura militar- hasta 1987 en la medida que la estrategia de movilización sufre un periodo de letargo por la hegemonía de la estrategia "electoralista" de la oposición a Pinochet. Aun cuando algunos

2 Esto refiere a lo que Manuel Castells (1999) denomina "identidades en resistencia".

3 Ver, por ejemplo, Weinstein (1989), Valenzuela (1984), Garcés y De La Maza (1985). 
comités en La Victoria ${ }^{4}$ aparecieron antes de 1983, es posible considerar esta fecha como "tiempo eje" para visibilizar una mayor masividad del movimiento de pobladores contra la dictadura de Pinochet, tanto en esta zona urbana en específico, como en términos más genéricos.

La población La Victoria es considerada un hito fundante del movimiento de pobladores en Chile y América Latina, ya que marcó una nueva forma de organización y consolida la presencia de los pobres de la ciudad en la lucha por sus derechos, es decir, los pobladores ya no eran visualizados como agentes pasivos sino como actores sociales identificables (Garcés, 2002; Espinoza, 1988). Junto a esta característica, lo que distingue a la población La Victoria de otras zonas urbanas, inclusive aledañas, son sus referentes identitarios en tanto fueron capaces de "representar" simbólicamente el mundo bajo una mirada de la resistencia contra la negativa del Estado por reconocer sus derechos sociales. ${ }^{5}$ Si bien este elemento no corresponde a una característica de excepción en esta zona urbana, sí es posible rotularla bajo lo que Alexis Cortés (2014) denomina como "ejemplaridad", entendiendo que poblaciones con referentes identitarios con casi la misma dimensión organizacional de La Victoria corresponden a una ínfima parte dentro del conjunto total de poblaciones santiaguinas $y$, por ende, marcaron ciertas pautas identificables a seguir para el resto.

Ahora bien, la discusión teórica relativa a problematizar la síntesis "identidad-historia" ha sido abordada bajo distintos campos epistemológicos como un fenómeno en el que un grupo de sujetos son capaces de recrear una imagen o narrativa de sí mismo/s y proyectarla/s frente al resto. (Giddens, 1995; Larraín, 2005, y Baeza, 2003). Pero a pesar de los intentos por dibujar una figura "fragmentada" de las identidades como lo han querido establecer algunos científicos sociales hechizados por tendencias postmodernas (Dubet, 1989), es posible detectar significativos elementos de unificación y horizontalidad en sociedades populares actuales en situación de vulnerabilidad, opresión o resistencia cotidiana (Castells, 1999). En lo relativo a las identidades colectivas como una reafirmación de sus repertorios culturales, Mercado y Hernández (2010) señalan que esta se proyecta como una serie de relaciones mediatizadas por procesos de sociabilización, y, por consiguiente, a los mecanismos de transmisión de normas, creencias y pautas valóricas que pretenden no ser borradas con el pasar del tiempo. En ese sentido, no es el peso de lo consuetudinario lo que determina la integración de estos al sistema de valores identitarios sino la participación de procesos de interacción

4 Actualmente la población La Victoria pertenece a la comuna de Pedro Aguirre Cerda, ciudad de Santiago de Chile. Limita al norte con Avenida 2 de abril, al sur con Avenida Departamental, al este con Avenida La Feria, al oeste con Av. Maipú o Línea Ferroviaria.

5 Paiva (1989), Lemuñir (1988), Farías (1989) y Morales (1989). 
comunicativa por medio de la construcción de lo social (Berger y Luckmann, 2000). Por su parte, la historiografía ha hecho eco de estas reflexiones principalmente desde los estudios culturales y la microhistoria. En ella, los estudios de las "mentalidades" -en tanto sólo examina componentes estructurales y mecánicos de las formas de sentimiento y pensamiento del pasado- son desplazados por las "representaciones" culturales cuyo encuentro con la antropología interpretativa de Geertz permite el ingreso a la historia de "personas concretas" o de "experiencias locales" (Chartier, 2012; Burke, 2006; Geertz, 1973).

Las discusiones teóricas relativas a los mecanismos de participación poblacional contra la dictadura militar se concentran en, a lo menos, tres referentes interpretativos. La primera lectura, es aquella de Manuel Garretón y Eugenio Tironi, quienes se basaron en condensar estas acciones colectivas bajo la lógica de que estas "resistencias poblacionales" expresaban pautas carentes de orientaciones "programáticas". De este modo, Tironi sitúa a las formas de resistencia poblacional entre la anomia y la violencia, contemplando actitudes de tipo reivindicativo, apático y disruptivo, en tanto las políticas de desarticulación social del régimen militar surtían efecto sobre la población (Tironi, 1987: 67). En una línea parecida, Garretón señala que las protestas de los pobladores eran fundamentalmente expresivas, desprovistas de contenido instrumental o reivindicativo preciso, donde lo que importa es la afirmación como sujeto de una identidad negada por la cotidianidad impuesta por la dictadura militar (Garretón,1987: 127). Una segunda posición, es aquella lectura "comunitarista" de Luis Razzeto, quien sugiere una interpretación del mundo poblacional bajo sus expresiones comunitarias, a efectos de entender sus posiciones de consenso y unificación -comités de alimentación, vestuario, capacitación, ahorro, salud, etcétera- antes que aquellas vinculadas al conflicto (Razzeto, 1987: 45). Una tercera interpretación es la expresada por Gabriel Salazar (2002 y 2012), cuya lectura de los pobladores se concentra en el componente autónomo de los sectores populares urbanos en sus mecanismos de participación y resistencia poblacional. En lo que respecta a este artículo, es posible señalar, a efectos de formular una hipótesis, que los mecanismos de participación durante el periodo 1983-1987 en población La Victoria vienen a reivindicar no sólo proyectos políticos o sociales sino reafirmar sus identidades culturales en tanto se recrea una identificación colectiva, contraria a la lógica dominante, como pensada para la organización política y social. En esto, se pretende orientar la reflexión en tres aspectos socio-culturales, la organización de comités, el arte muralista y las estrategias alimenticias como las ollas comunes, comprando juntos y otras iniciativas. 


\title{
Breve recorrido histórico de La Victoria e historicidad de las identidades colectivas victorianas, 1957-1983
}

\begin{abstract}
"Queremos que esta población sea el ejemplo de otras poblaciones y en realidad ya lo somos en parte, tenemos algo que otras poblaciones no tienen. Ese algo es el gran espíritu de superación que anida en el corazón de cada uno de nuestros habitantes. Por otra parte, nosotros no esperamos que nos solucionen nuestros problemas. ¡NO SEÑORES! Los problemas los solucionamos nosotros mismos". ${ }^{6}$
\end{abstract}

La Victoria fue fundada la madrugada del 30 de octubre de 1957 siendo la primera toma masiva de Latinoamérica, contando con casi cuatro mil familias aproximadamente, que con el pasar de los días se incrementarían. De acuerdo a Cristián Cabalin (2012), la toma se convirtió en uno de los hitos fundantes del movimiento de pobladores en Chile y América Latina, pues marcó una nueva forma de organización social a la fecha. He ahí que aparece una vasta gama de liderazgos ligados, mayoritariamente, al Partido Comunista (PC) y a la Iglesia Católica. Sobre el primero, la temprana presencia de pobladores comunistas no representó un elemento ajeno al origen del campamento, sobre todo cuando el Zanjón de la Aguada desde la década de 1940 alojó un enorme contingente de trabajadores salitreros emigrados a la ciudad tras la decadencia del sistema de oficinas e incursionando tempranamente en las luchas sindicales y partidistas del Norte Grande. El caso paradigmático es el de Juan Costa, boliviano de nacimiento y militante comunista, cuya capacidad de liderazgo y su experiencia política-militante, lo convirtieron en el primer presidente de La Victoria, siendo reelegido en reiteradas ocasiones (Garín, 2015, y Cortés, 2011). Por lo tanto, las directrices de la "cultura política" del PC de fines de los años '50 y principios de los '60 no eran desconocidas para los pobladores victorianos (Álvarez, 2011). Entre otros aspectos, su periódico local La voz de La Victoria recogía variadas fuentes de inspiración de los pasquines comunistas como Principios o El Siglo o, bien, sus directrices disciplinarias internas eran similares a los valores, reglas y normas de esta colectividad política. Parte de esta impronta se observa en la primera organización denominada Comité Central de Pobladores (CC) cuya máxima autoridad es el Secretario General, nomenclatura símil al organigrama político del PC.

Sobre el segundo, el liderazgo casi espontáneo de los sacerdotes católicos se hizo visible también desde el momento fundacional, sobre amplios espectros de la población, en su mayoría afines a la doctrina de la fe católica. El caso del padre argentino Del Corro, la intervención del cardenal José María Caro para evitar el desalojo en 1957, la ayuda técnica y material del Hogar

6 La Voz de la Victoria, 1-V- 1959: 4. 
de Cristo para estructurar la población, la presencia del Padre estadounidense Santiago Tijjerson ("El Padre Chago") durante la Unidad Popular, y para el periodo 1983-1987 los casos del Padre André Jarlan y Pierre Dubois, neurálgicos para reactivar la organización social (Verdugo, 1987).

Los pobladores desde 1957 hasta 1973 se constituyeron como uno de los movimientos más poderosos en términos de participación y politicidad, transformándose en una constante alarma para la institucionalidad burguesa que mira con desconfianza las prácticas de los pobladores en cuanto sus repertorios de acción amenazan el principio de la propiedad privada. Es por esto que la dictadura cívico-militar desde 1973 reprimió sistemáticamente aquellas poblaciones juzgadas comúnmente como organizadas -entre ellas La Victoria-, eliminando a sus principales líderes y desarticulando sus formas de organización local (Salazar y Pinto, 1999). Es posible asociar la etapa inicial de la dictadura, desde el Golpe Militar de 1973 hasta la primera jornada de protesta nacional en 1983, como un periodo de mayoritaria inmovilidad social, donde más bien predominan sentimientos de miedo, parálisis social y temor a reaccionar (Lechner, 1989). Por lo general, se asocia esta segunda etapa entre 1983 a 1987 como una de mayor politicidad y acción colectiva de los pobladores, aun cuando muchos elementos represivos más bien se intensificaron en esta época, más de lo que en otras podría existir:

"repetidamente los pobladores afirman que los uniformados presentaban el rostro de personas intoxicadas y en algunos casos con evidentes signos de ebriedad... A esto se suma lo brutal de las acciones represivas y el evidente desajuste de la conducta moral de los uniformados, con muestras de descontrol emocional y moral, como ocurre en los casos de agresiones a niños, ancianos, inválidos, o el caso extremo de militares que bailaban en ronda en torno a un poblador desnudo a quien obligaban a apagar con sus pies y manos una fogata, o a los casos de exhibicionismo de genitales y glúteos por parte de carabineros ante un grupo de pobladores en población La Victoria" (Análisis, 13-IX-1983: 20).

En lo que respecta las jornadas de movilización nacional contra la dictadura, es posible reconocer dos elementos de interés que permiten explicar el origen de la movilización popular contra Pinochet. El primero son los reiterados abusos del régimen en materia de derechos humanos y civiles, dada la naturaleza autocrática y represiva de este mismo y cuyo proyecto institucional, la Constitución de 1980, contó con el aval de las FF.AA. (Garcés y De la Maza, 1985; Schneider, 1990) y, en segundo lugar, la abismante crisis económica experimentada en Chile tras la crisis de 1982, que genera una enorme carga de frustración ciudadana. Tomás Moulian (1997: 279) señala que los niveles de cesantía en Chile fluctuaron en 1981, al 22,1\%, al 22,2\% 
en 1982 , un 19,2\% en 1983 y un $16,4 \%$ en 1984, siendo los más elevados del régimen militar y subsanados con programas precarizados de sub-empleo como el PEM y el POJH.

Los resultados de muerte durante la primera jornada de mayo de 1983, fueron de dos asesinados, Víctor René Rodríguez, poblador de la Santa Julia y Andrés Fuentes, en La Victoria. Este último era taxista y se encontraba en su casa al momento de los incidentes, al oír el ruido de la calle, se aproxima a la puerta, siendo asesinado por una bala perdida. El padre de Andrés, declaró lo siguiente a la prensa:

"Entraron a la población [carabineros] a balazo limpio. Nos trataban de comunistas y otras cosas. Hay casquetes de balas en todos lados. Uno de esos proyectiles disparados a menos de diez metros de distancia es el que causó la muerte a mi hijo. Todos vimos que era un carabinero, pero no pudimos identificarlo porque estaba oscuro, pero ellos eran los únicos que disparaban. ¿De dónde vamos a sacar armas nosotros?" (Las Últimas Noticias, 13-V-1983: 15).

\section{Identidades colectivas en La Victoria tardo-dictatorial: Formas de reafirmación de las identidades culturales, 1983-1987}

La mayor parte de las lógicas participativas de los primeros años de dictadura militar no derivan exclusivamente de los partidos populares de izquierda sino de organizaciones sin un perfil político (fingido o real) o de colectividades relacionadas a la Iglesia Católica. Siguiendo a Jaime Reyes (2014), La Victoria post-golpe se caracterizó por un perfil organizativo cercano a lo comunitario o al alero de la Iglesia Católica más que a las otroras colectividades marxistas. De esto mismo, aparece el Bloque Juvenil (1976), cuyo fin era juntar dinero -por medio de peñas folklóricas u otros eventos- para financiar comedores populares para niños, o el grupo Liturgia (1977), el que fue presidido por Miguel Zavala por muchos años, donde allí los sacerdotes Osvaldo Martínez y Sergio Nacer promovían algunos atisbos de participación local por medio de bolsas de trabajo -cuyo objetivo era ofrecer pequeños empleos temporales-y cursos de capacitación de artesanías o cocina. Un poblador recuerda esos años:

"Con Nacer, nosotros fuimos a dejar el primer muerto por la CNI... era el 77, no recuerdo bien, que lo mataron ahí en Callejón Lo Ovalle con Club Hípico más o menos...el cura Sergio Nacer fue, hizo todo el trámite, lo fuimos a velar... entre los tres estuvimos velando a la persona muerta, no apareció ningún familiar porque no se podía" (Entrevista personal, Juan Lemuñir, 2015). 
Recién en 1981 aparece el Comité de los sin Casa, primera alineación autónoma de la Iglesia que buscaba solucionar el problema de los allegados existentes en la población y que contaba con la participación de allegados de San Gregorio, Lo Valledor y La Legua. En octubre de 1982, casi dos mil allegados pertenecientes al Comité intentaron ocupar un terreno baldío entre avenida La Feria y calle Bombero Ossandón (hoy población Las Lilas, colindante a La Victoria), siendo violentamente desalojados por Carabineros y elementos de la CNI que rodearon la población movilizándose en automóviles sin patente (APSI, 8-X-1985: 10-1). En 1982, se funda el Comando de Pobladores, siendo Claudina Núñez - dirigente comunista-y Elizabeth Orrego sus principales caras visibles, entendiendo que hasta la fecha se conservaban la mayor parte de las directrices disciplinarias comunistas entre los pobladores victorianos (Hernández, 2013). Esto a su vez se nutre entre otras cosas, con el surgimiento del Frente Patriótico Manuel Rodríguez (FPMR) a fines de 1983, con una alta presencia y adhesión de las Milicias Rodriguistas en esta zona urbana.

"La sociedad estaba militarizada, tú vas a una parte y te encuentras con armas, encapuchados. Había ese discurso del derecho a autodefenderse. La lucha armada era parte de la auto-defensa del pueblo. Había que mostrar el descontento. Tenían temor del Frente. Hartos pertenecieron. Pero también ayudaron a la población en momentos críticos. Trajeron camiones de pollo, camiones con alimentos a la población, para los más pobres, no había ni un rechazo ahí" (Grupo de trabajo La Victoria, 2006: 144).

A la larga, el enrroque producido por los sacerdotes Osvaldo Martínez y Sergio Nacer con los sacerdotes francoparlantes Pierre Dubois y André Jarlan en febrero de 1983 fue beneficioso en las estructuras organizativas de los pobladores victorianos. Una de las principales creaciones fueron los denominados vulgarmente "comités de los volaos", cuyo fin era rehabilitar jóvenes y adultos ahogados por el incipiente consumo e introducción de drogas y estupefacientes y donde participaban monitores tanto jóvenes estudiantes como jefas de hogar, y el de misión obrera, destinado a jóvenes obreros católicos. Carlos Cuevas, un joven poblador, lo recuerda con dichas características: "ayudaba a toda la gente de la población. Formó varios grupos para organizar a los jóvenes, yo participé en dos: "misión obrera" y en el grupo de los "volados" que ayudaba a rehabilitar jóvenes drogadictos" María Sánchez recuerda a Jarlan: "Era el hombre de la eterna sonrisa (...) buscaba a los jóvenes 'volados' para ayudarlos. Pedía la unidad de la gente. ¿Y cómo lo mataron? En su pieza, leyendo la biblia...esto es lo último que puede existir" (Solidaridad, 21-IX-1984: 22).

A su vez, la intensificación de la protesta social y política opositora a la dictadura militar desde mayo de 1983, obligó a la reevaluación local de las 
prácticas médicas realizadas por los comités de la población para evitar que pobladores heridos en las protestas sean atendidos en centros de salud pública y, por ende, arrestados por agentes represores o de información del Estado. Si bien el Comité de Salud Poblacional, según Manuel Paiva (1988), existía desde el año 1980, esta organización no fue suficiente para el contexto de 1983, de acaparar la enorme cantidad de heridos como saldo que dejaban las protestas nacionales en La Victoria, sobre todo, cuando en la mayoría de los casos, los comités carecían de los recursos médicos necesarios y las monitoras manejaban una formación elemental y autodidáctica, obligando en la mayoría de los casos al traslado a heridos de extrema gravedad al Hospital Barros Luco. Pierre Dubois facilitaba su camioneta para el traslado de heridos hacia este centro de atención pública (Lemuñir, 1988).

El sacerdote francés Pierre Dubois planteaba la idea de la "no-violencia activa", que significaba tanto la desobediencia civil pacífica y movilizada de Gandhi como la experiencia evangélica de Jesucristo predicando y juntándose con las prostitutas y cobradores de impuestos e indicando que la acción de amar al prójimo era lo fundamental (Santapau, 2006). Por ende, el "hacerse pobre entre los pobres" significaba dar la vida por la causa por los oprimidos, homologando a Jesús y a sus discípulos que fueron perseguidos por practicar su fe, en medio de una época donde se percibe una profunda violación a cualquier principio de justicia social. El Padre Pierre, a diferencia del Padre Jarlan, se caracterizaba por una posición favorable a la participación interna como a la de protección a los pobladores, acaso la más simbólica y valiente de estos recuerdos debe ser aquella donde se puso debajo de las ruedas de una tanqueta militar para evitar que estos avanzaran violentamente hacia la población (Archivo Vicaria de la Solidaridad, Doc. 1106, 2-X-1985).

Sin embargo, parte de los progresos obtenidos en materia organizativa se vieron parcialmente truncados con el asesinato del padre André Jarlan a consecuencia de una bala "loca" de carabineros el 4 de septiembre de 1984 (Verdugo, 1985), como de la expulsión del Padre Pierre Dubois, días después del atentado adjudicado por el FPMR contra Pinochet, el 8 de septiembre de 1986, donde en las consecuentes operaciones y fuerte represión policial y militar posterior hacia distintas poblaciones del país, arrestan y posteriormente expulsan a Dubois del país, junto a dos sacerdotes franceses, bajo el argumento de "constante injerencia en actividades políticas internas e incluso en actos de agitación y subversión del orden público" (Las Últimas Noticias, 12-IX-1986: 12). Si bien el liderato de Dubois era uno de los más relevantes en el funcionamiento de la estructura organizativa en La Victoria, no provoca un estado de acefalía drástico que condujera a un declive de esta misma o un vacío de poder tan profundo. Básicamente, esto tiene como respuesta el hecho de que coexistían una amplia gama de comandos dentro de la población, no dependientes de lideratos mesiánicos: el Comité 
de Cesantes, el Comando de Salud Poblacional, el Comando de la Olla común, y los Comandos de Pobladores y el Comité de los Sin Casa. Gracias a los esfuerzos del Padre Pierre, estas coordinadoras van a tomar contacto con organizaciones de DD.HH. y ONG del viejo continente (Suiza, Alemania y Francia, principalmente), quienes consiguen fondos para reeditar programas como el de Leche por Cuadra -que se terminó tras la partida del Padre Pierre-, las Colonias Urbanas, los Comederos Populares y Comprando Juntos (Santapau, 2006). De acuerdo al testimonio de Carlos Aravena, presidente de la comunidad cristiana de La Victoria:

"Él nos contó que está tratando de conseguir recursos en su diócesis de Francia y nosotros tenemos que tenerlo todo listo, con un delegado por cuadra y una encuesta casa por casa. También debemos organizar el pesaje de los niños para después evaluar los resultados... En realidad Pierre Dubois está presente en cada actividad que se realiza en la Victoria. En la semana del 4 de septiembre que conmemora a André Jarlan, en cada cuadra se hicieron 'porotadas'" (Análisis, 27-IX-1987: 19).

Clandestinamente, el padre Pierre se reunía en Mendoza con pobladores victorianos, principalmente Elizabeth Orrego, presidenta del Comando de Pobladores, y Carlos Aravena. Parte de estos encuentros tenían como objetivo entregar dineros para financiar los programas truncados tras su partida (Hoy, 15-XI-1987: 14-5). El caso del Padre André Jarlan es simbólico, partiendo de la premisa que fue la primera muerte reconocida por el régimen propiamente tal (Alcatruz, 2007). Un testimonio de una pobladora nos relata el final de André Jarlan:

"Yo con él, estaba en el primer año de catequesis y fue muy doloroso. Esa noche fue la más penosa que he podido pasar, de lacrimógenas, de gritos, de disparos, gritos, fue terrible el acordarme, es como retroceder a mi niñez... luego se le veló en la iglesia y ahí caminar con toda la gente no sólo de La Victoria, de muchas partes hasta la catedral de Santiago, fue muy emocionante" (Entrevista personal, Marcela Cerda, 2016).

Algunos mecanismos participativos de supervivencia como las denominadas "ollas comunes" pareciesen ser percibidas, en apariencia, como una actividad específicamente paliativa, pero en realidad poseía un trasfondo político-partidista, por un lado, y de organización interna por el otro. De acuerdo con la historiadora Francisca Espinoza (2014), la mayor parte de los gestores de esta medida reconocían vinculación con el PC. El presidente del comité de la olla común en 1983 fue el ex dirigente y militante comunista Lázaro Pérez. En una entrevista, contaba que allí la cesantía era de un $70 \%$ y en su caso, sólo en su núcleo familiar de 23 personas, cuatro tenían trabajo en los programas de empleo del régimen militar. Pérez no trabajaba desde 
1973, y debido a su pasado (dirigente sindical y presidiario en Chacabuco) no le dan empleo en los programas del PEM y POJH. Además, considerando que en el momento de la entrevista tenía 56 años, es visto, de acuerdo a lo expuesto por el entrevistado, como "un viejo" (APSI, 2-VIII-1983: 23). En esta misma línea, Pérez reconocía el posterior liderazgo de Olga Donoso, a la postre, la creadora de esta misma iniciativa. Ella también era militante del PC y encargada de la olla común por muchos años. Según Donoso, "empecé con un fondo porque no alcanzaba para nada más. Costó mucho armar esto, porque al principio todos se horrorizaban. Les daba vergüenza pedir un plato de comida, pero después se les hizo claridad" (APSI, 6-X-1985: 12). Esta referencia también es interesante en cuanto considera una nueva arista del problema que es la conformación de espacios clandestinos de discusión política con estrategias de subsistencia.

"Así el Partido Comunista fue un bastión clave para la organización de distintas iniciativas -como lo señala Flor, una ex militante-: "el Comité Sin Casa y la Olla Común netamente era comunista, porque las manejaban los comunistas, porque las reuniones del partido, las células, de todo eso, hablaba de la organización de la olla, del comité sin casa, se hablaba de toda esa organización social política" (Espinoza, 2014: 31).

Un elemento similar al de la "olla común" era el programa Comprando Juntos, formado en 1983, el que agrupaba a casi quinientas familias, al que con el pasar de los años se fueron integrando más y cuya función era proveer alimentos comprando a ferianos de Lo Valledor (cruzando la Línea ferroviaria) y el Matadero (Franklin) distintos bienes alimenticios al por mayor, para reducir costos familiares (Análisis, 2-VIII-1983: 21-23).

En esta coyuntura, aparece el famoso "arte mural", cuya actividad se mantenía censurada y perseguida por la dictadura militar desde 1973. Antes del golpe, este tipo de arte popular se concentraba en espacios públicos de enorme concurrencia como Cerro Santa Lucía, Sewell, los Tajamares del Mapocho, MAC, entre otros lugares, para manifestar su adhesión a la Unidad Popular (Saul, 1972). Sin embargo, desde 1983 emergen algunas brigadas, esta vez dentro de poblaciones combativas, tanto para configurarse como un interlocutor crítico de la dictadura militar como para reafirmar hitos de corte local en sus dibujos muralistas (Alcatruz, 2007 y 2011). Este arte colorido, sencillo de pintarrajear y de fácil entendimiento, buscaba representar las principales problemáticas desarrolladas en el marco de la dictadura (represión, atropellos a los DDHH, cesantía, violencia sistemática, pobreza, censura) como remembrar hechos representativos de la historia pasada y reciente de La Victoria, entre ellas, la toma del terreno (1957) el rol de las mujeres en la construcción de esta zona urbana, el golpe militar de 1973, la muerte del padre André Jarlan (1984) y el exilio forzoso del padre Pierre Dubois (1986). 
Cabe señalar que existen registros murales muy limitados en La Victoria durante los últimos años de dictadura militar, puesto que eran borrados por órdenes municipales o grupos oficialistas destinados para ese fin. Corroborando esta idea, un edicto municipal de abril de 1985, ordena borrar todos los murales de La Victoria incluyendo aquellos que pedían "justicia para el Padre Andrés" (APSI, 4-V-1985: 22). Estos murales, sin embargo, volvían a aparecer a las pocas semanas o días. Así, uno de los escasos registros fotográficos de esta temática se encuentra plasmada en la memoria de título de la artista visual Ebe Bellange (1987), quien expone murales que recuerdan la figura de André Jarlan en La Victoria y otras temáticas suscitadas en torno a la violencia ejercida por la dictadura militar.

Figura 1

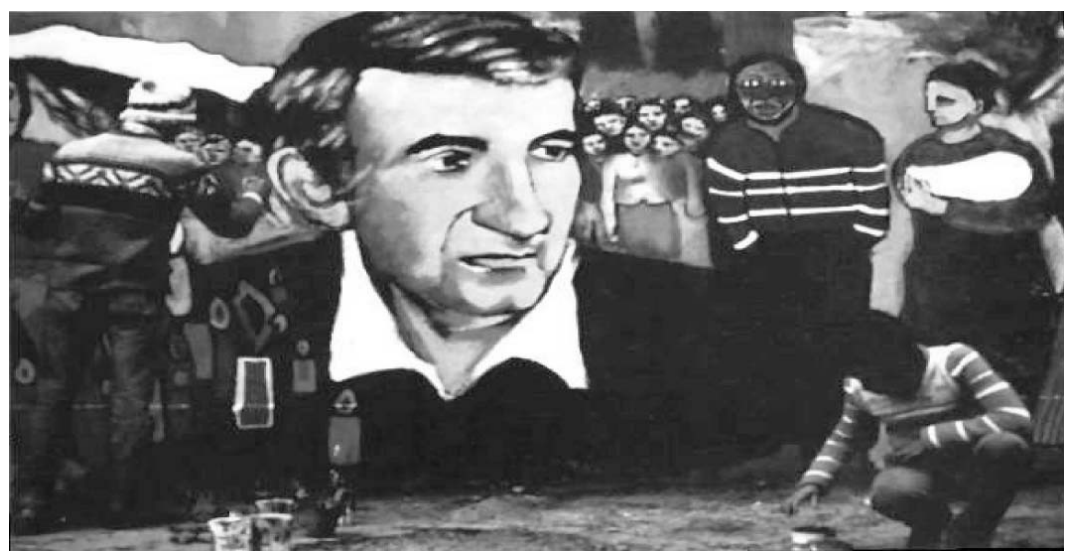

Fuente: Bellange, 1987: 50.

En la fotografía anteriormente expuesta, nótese la imagen del Padre Jarlan como cara visible de los "caídos" por la violencia sistemática de la dictadura militar y, al mismo tiempo, símbolo de la resistencia poblacional contra la opresión militar. Esto es un aspecto no menor puesto que este hito contribuye a la construcción de memorias colectivas del pasado reciente bajo una narrativa identitaria en La Victoria (Garín, 2014).

\section{Conclusiones}

Entre otras aspectos, el nexo entre identidad colectiva -entendida como reflexión grupal del yo- y participación social en La Victoria tiene como principal correlato, no sólo la sentencia de que estas acciones vienen a reivindicar programas o proyectos políticos -acaso el más próximo, el de resistir y acabar con la dictadura de Pinochet- sino identificaciones en términos culturales, asociadas a la organización, a la autonomía de estas formas, los códigos 
simbólicos tras estos referentes identitarios, elementos consustanciales al mundo popular de los pobladores.

A pesar de esta referencia, comúnmente considerada intrínseca a la cultura popular, lo meramente particular del caso de La Victoria es que marca un patrón conductual considerado bajo la categoría de "ejemplaridad", ya sea por los altos índices de historicidad de sus estrategias de organización que no sólo se presentan entre el ciclo 1983-1987, frecuentemente considerado una coyuntura significativa de reestructuración social y política contra la dictadura militar en el contexto de las jornadas de protesta nacional, sino desde 1957. Aun así, el ciclo 1983-1987 viene a reivindicar variados mecanismos de participación social en términos que la "resistencia" a la dictadura no sólo puede ser representada en términos de la búsqueda de un proyecto alternativo a la lógica dominante sino también en concepciones, imaginarios, símbolos, ritos, liturgias, representaciones y otros que configuran un espacio cultural en disputa que alimenta tanto las "culturas políticas" de los sujetos populares como sus identidades populares, no necesariamente desarrolladas bajo el alero de las colectividades partidistas.

Precisamente esta resistencia del mundo de los pobladores hacia lo político-partidista ha sido mal interpretada como un signo de anomia por parte de algunos teóricos ya señalados, como Tironi o Garretón, quienes por el contrario reivindican lo "comunitario" en tanto tónica general del "pertenecer" a una clase social determinada, y sus historicidades, experiencias y formas de horizontalidad. Esto define y no otra, las formas de pensamiento y sentimiento de lo popular en Chile.

\section{Referencias Bibliográficas}

\section{Fuentes primarias}

a) Archivos

Archivo Vicaría de la Solidaridad, Documentos Nº1106 y 1316.

b) Periódicos y revistas

La Voz de la Victoria, Santiago, 1959.

La Segunda, Santiago, 1983- 1986.

Las Últimas Noticias, Santiago, 1983-1986.

Revista Análisis, Santiago, 1984-1986.

Revista APSI, Santiago, 1984-1986. 
Revista Hoy, Santiago, 1987.

Revista Solidaridad, Santiago, 1984-1986.

c) Entrevistas

Juan Lemuñir, Poblador de La Victoria, 2015.

Marcela Cerda, Pobladora La Victoria, 2016.

\section{Fuentes secundarias}

\section{a) Artículos}

Alcatruz, P. (2007). "Aquí se pinta nuestra historia: el muralismo callejero como acercamiento metodológico al sujeto popular", en Anuario de Pregrado, Santiago: Universidad de Chile.

Cabalin, C. (2012). "Identidad cultural y ciudadanía en los sectores pobres de Santiago de Chile" en Perfiles Latinoamericanos, México D.F.: Vol. XX.

Cortés, A. (2007). "Los comunistas y las tomas de terreno: a 50 años de una de las tomas más grandes de Latinoamérica", en Alternativa. ICAL: Vol. XXV.

Cortés, A. (2014). "El movimiento de pobladores chilenos y la población La Victoria: ejemplaridad, movimientos sociales y derecho a la ciudad", en Revista Eure. Vol. XL, №119.

Dubet, F. (1989). "De la sociología de la identidad a la sociología del sujeto", en Estudios sociológicos, VII, № 21.

Espinoza, F. (2013). "La vida no era pa' estar en la casa sino pa' estar en la calle. Olla común y tensiones de género en la población La Victoria, 1980-1989", en Seminario Simon Collier, Vol. IV. Santiago: Instituto de Historia, Pontificia Universidad Católica de Chile.

Farías, G. (1989). "Lucha, vida, muerte y esperanza. Historia de la Población La Victoria", en Constructores de ciudad, nueve historias del primer concurso de Historia de poblaciones. Santiago: Editorial Sur, pp. 49-63.

Garín, E. (2017). "Dos sacerdotes franceses en Población La Victoria: André Jarlan y Pierre Dubois y la No-Violencia activa durante la dictadura militar (19831986)", en Revista Historia en Movimiento, Vol. V. Concepción: Universidad de Concepción (en prensa).

Garín, E. (2015). "Jornadas de protesta nacional y movimiento de pobladores en Chile: el caso de La Victoria (1983-1987)", Ponencia presentada al I Seminario de Movimientos Sociales en América Latina y el Caribe, Universidad ARCIS. 
Garín, E. (2014). "Microhistoria de La Victoria, la figura del padre André Jarlan en sus expresiones patrimoniales", en Sapiens, Vol. IV. Santiago de Chile.

Garretón, M. (1987). "Las complejidades de la transición invisible, movilizaciones populares y régimen militar en Chile", en Proposiciones, Vol. XIV. Santiago: Editorial SUR.

Mercado, A. y Hernández A. (2010). "El proceso de construcción de identidad colectiva", en Convergencia, № 53. México D.F.

Reyes, J. (2014). "El Partido Comunista y las tomas de terreno bajo la dictadura: los "combates" por la vivienda 1980-1984", en Revista de Historia social y de las mentalidades, Vol. XVIII. Santiago: Universidad de Santiago de Chile.

Robles, M. (2013). "Historia de la organización de los pobladores de las Barrancas (entre la autonomía, la participación, y la desobediencia civil de los pobladores 1930-1984)", en Palimpsesto. Santiago: Universidad de Santiago de Chile.

Salinas, M. (1992). "La búsqueda de un lugar sagrado, la trayectoria social y religiosa del mundo poblacional 1962-1992", en Trocadero. Cádiz: Universidad de Cádiz.

Schneider, C. (1990). "La movilización de las bases, poblaciones marginales y resistencia en Chile autoritario", en Proposiciones, Vol. XIX. Santiago: Ediciones SUR.

Tironi, E. (1987). "Marginalidad, movimientos sociales y democracia", en Proposiciones, Vol. XIV. Santiago: Ediciones SUR.

\section{b) Libros}

Álvarez, R. (2001). Arriba los pobres del mundo, Cultura e identidad política del Partido Comunista de Chile entre democracia y dictadura 1960-1990. Santiago: LOM.

Baeza, M. (2000). Los caminos invisibles de la realidad social: Ensayo de sociología profunda sobre los imaginarios sociales: Santiago: Editorial RIL.

Bellange, E. (1987). El muralismo como reflejo de la realidad social. Santiago: LOM-USACH.

Berger, P. y Luckmann, T. (2000). La construcción social de la realidad. Buenos Aires: Amorrortu Ediciones.

Burke, P. (2006). Formas de historia cultural. Madrid: Editorial Alianza.

Castell, M. (1999). La era de la información, economía, sociedad y cultura. El poder de la identidad. Volumen II. Madrid: Editorial Alianza. 
Chartier, R. (1992). El mundo como representación. Ensayos de historia cultural. Madrid: Gedisa.

Espinoza, V. (1987). Para una historia de los pobres de la ciudad. Santiago: Editorial Sur.

Garcés, M. (2002). "Tomando su sitio" el movimiento de pobladores de Santiago. 1957-1970. Santiago: LOM.

Garcés, M. y De la Maza Gonzalo (1985). La explosión de las mayorías, protesta nacional 1983-1984. Santiago: ECO.

Geertz, C. (2006). La interpretación de las culturas. Barcelona: Editorial Gedisa.

Giddens, A. (1995). Modernidad e identidad del yo; el yo y la sociedad en la época contemporánea. Barcelona, Editorial Península.

Grupo de Trabajo La Victoria (2006). La Victoria, rescatando su historia. Santiago: Ediciones UARCIS.

Jelin, E. (2002). Los trabajos de la memoria. Buenos Aires: Editorial Siglo XXI.

Larraín, J. (2005). ¿América Latina moderna? Globalización e identidad. Santiago: LOM.

Lechner, N. (1989). Los patios interiores de la democracia, subjetividad y politica. Santiago: FLACSO.

Lemuñir, J. (1988). Crónicas de La Victoria: Testimonio de un poblador. Santiago: Ediciones Documentas.

Moulian, T. (1997). Chile, anatomía de un mito. Santiago: Editorial LOM-ARCIS. Morales, C. (1987). La Victoria de Chile. Santiago: Editorial Llaima.

Salazar, G. y Pinto, J. (1999). Historia Contemporánea de Chile, Tomo I, Estado, legitimidad y ciudadanía. Santiago: LOM.

Salazar, G. (2003). Violencia política popular en las grandes alamedas. Santiago: LOM.

Paiva, M. y Grupo de Salud Poblacional (1987). Pasado, victoria del presente. Santiago, s/e.

Thompson, E. P. (1989). La formación de la clase obrera en Inglaterra. Madrid: Editorial Crítica, Tomo I.

Valenzuela, E. (1984). La rebelión de los jóvenes. Un estudio de anomia social. Santiago: Ediciones Sur.

Verdugo, P. (1987). André de la Victoria. Santiago: Ediciones Aconcagua. 
Weinstein, J. (1989). Los jóvenes pobladores en las protestas nacionales (19831984): una visión socio-política. Santiago: CIDE.

\section{c) Tesis}

Alcatruz, P. (2011). Las paredes tienen historia: murales barriales contemporáneos en Buenos Aires (Argentina) y Santiago (Chile), Tesis para optar al grado de Magíster en Estudios Latinoamericanos. Santiago: Universidad de Chile.

De la Torre, P. y Acuña, M. (2004). El arte muralista de las Brigadas Ramona Parra 1967-1973, Seminario de titulación para optar al grado de Licenciado en Historia. Santiago: Universidad de Chile.

Hernández, J. (2013). Participación ciudadana. El caso de la alcaldía de Claudina Núnez en la Comuna de Pedro Aguirre Cerda (2008-2012), Tesina para optar al grado de Licenciado en Historia. Santiago: Universidad Diego Portales.

Santapau, D. (2006). El evangelio hecho acción: sacerdotes franceses y pobladores de La Victoria (1983-1986), Tesis para optar al grado de Licenciado en Historia. Santiago: Pontificia Universidad Católica de Chile. 